\title{
Correlations between Foot Sensory Impairment, Timed Up and Go Test and Berg Balance Scale, and Mental Activities for Prevention of Falling in Elderly People
}

\author{
Young-Ho Lee · Seon-Jung Jang • Gi-Beom Kang • Ye-Seul Choi • Young-In Hwang ${ }^{\dagger}$
}

Department of Physical Therapy, College of Life and Health Science, Hoseo University

Received: July 23, 2019 / Revised: August 3, 2019 / Accepted: September 11, 2019

(c) 2019 J Korean Soc Phys Med

\section{| Abstract |}

PURPOSE: This research was designed to study the correlations between physical activities such as foot sensory impairment, balance and ambulatory abilities, as well as fall risk factors and mental activities such as cognitive performance and depression in order to provide fundamental data for the prevention of falling in the elderly.

METHODS: A total of 36 elderly people over the age of 65 years who voluntarily joined the research were selected as subjects. Sensory perception in both feet was measured by using a monofilament in 10 parts with each part given one point. The points for each foot were integrated to analyze the correlations between physical and mental activities indices, and the results were analyzed by using Pearson's correlation coefficient.

RESULTS: The results of this research show that the extent to which senses in feet were impaired was correlated to TUG, a functional activity index involved in tranfers, gait, and

†Corresponding Author : Young-In Hwang young123@hoseo.edu, https://orcid.org/0000-0002-7314-1678 This is an Open Access article distributed under the terms of the Creative Commons Attribution Non-Commercial License (http://creativecommons.org/licenses/by-nc/3.0) which permits unrestricted non-commercial use, distribution, and reproduction in any medium, provided the original work is properly cited. turning movements, which was correlated to BBS (balance index) as well as MMSE-K and K-GDS (mental activities index). BBS was interrelated to FES-K (physical activities index) and MMSE-K. The muscular strength of the right ankle dorsiflexor had mutual relations with FES-K.

CONCLUSION: The results of this research indicate that TUG is widely correlated to foot sensory impairment as well as general physical and mental activities in elderly people. BBS was also shown to be correlated with TUG, FES-K, and MMSE-K. Thus, it might be necessary that TUG and BBS be included as two items in physical and mental check-ups for the elderly, and further studies on correlations using evaluation items for physical and mental activities should lead to the simplification of the evaluation criteria.

Key Words: Balance, Cognition, Depression, Elderly people, Fall-down

\section{Introduction}

The occurrence of balance and gait disturbance in the elderly results in falling, causing great physical disorder in everyday life activities and even death in serious cases [1]. Every year, $35 \%$ of the elderly over 65 -years-old as well as $50 \%$ over 80 -years-old suffer falling at least once [2], 
and more than $30 \%$ experience it again [3]. One out of 10 sustains serious damage, including hip fractures, subdural hematomas, and traumatic brain injuries [4]. Regardless of general health condition, falling occurs more frequently in people who move less, which is closely related to cases in which they reduce their housekeeping work, dressing or undressing, and personal hygiene like washing one's face $[5,6]$.

One of the risk factors of falling is one's mental state, which refers to the fear of falling. Around $50 \%$ of people who have this kind of fear are restricted or isolated from major social and physical activities [7]. In turn, this can cause fear of stress and falling in a vicious cycle where posture can worsen, gait velocity slow, muscular strength weaken, and quality of life can deteriorate [7].

Another risk factor is related to cognitive disorders. The Mini-Mental State Examination conducted on a group of people with less than 24 or 26 points suggested that the risk factor of falling increased in this group [8]. Longitudinal Aging Study Amsterdam (LASA) reported that elderly people over 75-years-old with severe memory loss also had the same risk factor [9].

Unlike the mental risk element of falling, the physical risk of falling affects the feet. Callus under the big toe, flaws affecting the long toes, ulcers, transformed toenails, and feet pain while walking prevent proper balance, resulting in falling [10]. Besides, diabetes or feet sensory impairment caused by disorders of the peripheral nervous system can increase risk of falling [11].

Therefore, this research targeting general elderly people focused on studying the correlations between physical activities, such as foot sensory impairment, balance and ambulatory abilities, falling risk factors, and daily life criterion, and mental activities such as cognitive performance as well as depression in order to analyze the extent to which foot sensory impairment is risky, and the results can be used as a future resource for prevention of falling in the elderly.

\section{Methods}

\section{Subjects}

This research was conducted on 36 elderly people over 65 years of age. The local subjects who voluntarily joined the research resided in the Asan and Chengju areas. The inclusion criteria for the subjects were as follows: (a) Individuals who could walk independently or used assistive devices, (b) Individuals who could follow simple directions, and (c) Individuals without severe foot pain or orthopedic problems. The exclusion criteria were as follows: (a) Disabled individuals due to central nerve injury, (b) Individuals not able to walk due to severe knee, hip joint, and back pain, and (c) Individuals with a severe cognitive disorder. Each subject was offered a document authorized by the Institutional Review Board of Hoseo University (1041231-180821-HR-084-05).

\section{Measurement}

\section{1) Foot sensory impairment (FSI)}

The foot sensory impairment (FSI) test used was Semmes-Weinstein Monofilament (4.56). In order to assess the foot sensation response by applying pressure on the foot with the filament (4.56), all subjects were seated in a comfortable chair in a stable environment. Before performing the test, each participant was acclimated to touch sense in the inside of the wrist [12]. Then, the legs were straightened, and the monofilament was applied to 10 areas of the bare foot to assess the presence of sensation on both sides. The area was as follows: (1) hallux, (2) $3^{\text {rd }}$ toes, (3) $5^{\text {th }}$ toes, (4) $1^{\text {st }}$ metatarsal head, (5) $3^{\text {rd }}$ metatarsal head, (6) $5^{\text {th }}$ metatarsal head, (7) medial mid-foot, (8) lateral mid-foot, (9) heel, and (10) dorsal surface of the foot between in the first and second toes [12,13]. After placing the filament at $90^{\circ}$ to the skin surface, pressure was applied for 1 second to determine if it could be felt or not [12]. Tests were carried out in these areas three times. One out 
of three times, the investigators assessed feeling without pressing on the skin. If feeling sensation could not be perceived for more than two of the three questions, it was assumed that the examined area was numb [14]. After calculating the number of parts that experienced no sensation, each part with no sensation was given one point. Finally, points for all parts with no sensation were combined.

\section{2) Gait and balance measurement: Timed Up and Go} Test and Berg Balance Scale

(1) Timed Up and Go Test (TUG)

Subjects first sat on chairs, and at the word of command "Start", subjects walked up to 3 meters to an obstacle, returning to their chairs around the obstacle to sit again. The time during which the subjects started to go and come back was measured in seconds. Subjects were asked to stand up and walk without using armrests. They were directed to go around the obstacle from left to right.

(2) Berg Balance Scale (BBS)

BBS is an evaluation tool designed to measure balance in the elderly and is composed of a total of 14 items [15]. Each item is made up of five points ranging from zero to four (zero in the case that an assignment is completely undone and four points for perfectly done) [15]. Total points range from zero to 56 . Higher points mean that subjects more perfectly perform their assignments. Inter-rater reliability of BBS turned out to be .95 (95\% confidence interval [CI], .93-.97) with a test-retest reliability of .98 .

\section{3) Muscular strength: Digital handheld dynamometer}

In order to evaluate muscular strength of the ankle dorsiflexor and ankle plantarflexor in the elderly, strength was measured for 5 seconds by using Mirco FET II in an upright sitting position with the hip, knee, and ankle at about 90 degrees during isometric contraction [16]. After measuring maximum strength three times, the average value was calculated.

\section{4) Falls Efficacy: Fall Efficacy Scale}

For production of Falls Efficacy, the Korean version of FES-K, which was supplemented and revised for Korean elderly people, was used. The measurement scale of each item was composed of four points (one point for "I am not able to do anything" and four points for "I am able to do everything very well"). Higher score means higher self-confidence of a perfect everyday life without falls.

\section{5) Cognitive Disorder: Mini-Mental Status Examination- Korean (MMSE-K)}

The Korean version of the Mini-Mental State Examination was used to examine orientation as well as the state of cognition related to language. Exactly $85.7 \%$ of Korean experts who conduct mental status examinations choose to evaluate the early stages of dementia and progression of the disease [17]. MMSE-K consists of items that respond discriminately to patients with depression and dementia. According to analysis of the items, the symptoms of the early stages of dementia and depression can be sorted out [18].

\section{6) Depression: Korean Form of Geriatric Depression Scale (K-GDS)}

The Korean version of the Geriatric Depression Scale, which consists of 30 items (16 negative and 14 positive questions) with responses of "Yes" or "No", was used. Negative questions are given one point for "Yes" and zero points for "No", and positive questions are converted to an inverse score of zero points for "Yes" and one point for "No". K-GDS's Chronbach`s a of .88 and split-half reliability of .79 was used [19].

\section{Procedure}

All subjects were asked to be examined by selecting five examination items randomly related to balance, fall 
Table 1. Characteristics of Subjects

\begin{tabular}{ccccc}
\hline & Gender & HTN & DM & \\
\hline $\mathrm{N}(\%)$ & $\begin{array}{c}\text { Male 6 }(16 \%) \\
\text { Female 30 }(83 \%)\end{array}$ & $23(63 \%)$ & $14(38 \%)$ & \\
\hline Mean \pm SD & Age (years) & Heights $(\mathrm{cm})$ & Weights $(\mathrm{kg})$ & BMI $\left(\mathrm{kg} / \mathrm{m}^{2}\right)$ \\
\hline & $79.42 \pm 6.12$ & $152.86 \pm 6.26$ & $58.95 \pm 19.24$ & $25.23 \pm 7.98$ \\
\hline
\end{tabular}

HTN: Hypertension, DM: Diabetes

efficacy, and muscular strength. For the BBS and TUG examinations related to balance, the tester carried out an examination along with a research assistant to prevent risk factors. It took 15 30 minutes to complete the BBS evaluation. Meanwhile, TUG was carried out three times with a 5 minute break in between examinations. In case that the subjects wanted to rest, breaks were given while measuring a total of three times and calculating the average. Examinations of depression and cognitive disorders were carried out independently after enough rest following a physical check-up.

\section{Data analysis}

To analyze the correlations of data on foot sensory impairment with physical and mental activities in the elderly, SPSS (ver. 20.0 for window; SPSS, Inc, Chicago, Il, USA) was utilized, with Pearson's correlation coefficient used as a statistical analysis method. The significance level was an a less than $.05(\mathrm{p}<.05)$.

\section{Results}

A total of 36 subjects (six males, 30 females) were participated. The dominant foot of each subject was the right foot. Patients with hypertension numbered 23 while those with diabetes numbered 14 . The average age was $79.42 \pm 6.12$ years, average height was $152.86 \pm 6.26 \mathrm{~cm}$, average weight was $58.95 \pm 19.24 \mathrm{~kg}$, and BMI was $25.23 \pm 7.98 \mathrm{~kg} / \mathrm{m}^{2}$ (Table 1).

It was found out that foot sensory impairment of subjects' feet was $4.06 \pm 4.70$ points on average. In the case of physical activity, TUG was $14.37 \pm 4.15$ seconds, and BBS was $47.42 \pm 5.56$ points. In terms of force, muscle strength of the right ankle dorsiflexor was $8.36 \pm 4.06$ $\mathrm{kgf}$, left ankle dorsiflexor $8.34 \pm 4.41 \mathrm{kgf}$, right ankle plantarflexor $6.85 \pm 3.94 \mathrm{kgf}$, and left ankle plantarflexor $7.35 \pm 3.95 \mathrm{kgf}$ (Table 2).

The results of the correlations between foot sensory impairment as well as physical and mental activities show that the FSI of both feet had low correlations with TUG $(r=.349, p=.037)$. Meanwhile, there was no correlation with physical or mental performance. TUG was found to be negatively moderately correlated with BBS $(\mathrm{r}=-.501$, $\mathrm{p}=.002)$, lowly with MMSE-K ( $\mathrm{r}=-.392, \mathrm{p}=.008)$, and moderately with K-GDS ( $r=.479, \mathrm{p}=.003)$. BBS showed a low correlation with FES-K $(r=.380, p=.022)$ and moderate correlation with MMSE-K $(\mathrm{r}=.473, \mathrm{p}=.008)$. FES-K showed a highly negative correlation with K-GDS $(r=-751, p=.000)$ and low negative correlation with the right ankle dorsiflexor ( $\mathrm{r}=.331, \mathrm{p}=.049)$. MMSE-K was shown to have a moderate, negative correlation with K-GDS ( $r=-.433, p=.008)$ (Table 3).

\section{Discussion}

This study proposes the hypothesis that foot sensory impairment and physical activities such as gait, balance, and force are mutually related to mental performance such as falls efficacy. Foot sensory impairment, however, was found to be solely correlated with TUG (gait measurement: 
Table 2. Averages of Foot Sensory Impairment and Physical and Mental Activities in Elderly People

\begin{tabular}{ccc}
\hline & Parameters & Mean \pm SD \\
\hline Physical Activity & FSI (points) & $4.05 \pm 4.69$ \\
\hline Gait & TUG (sec) & $14.36 \pm 4.14$ \\
\hline Balance & BBS (points) & $47.41 \pm 5.56$ \\
\hline & RAD (kgf) & $8.36 \pm 4.05$ \\
Muscle Strength & LAD (kgf) & $8.34 \pm 4.40$ \\
& RAP (kgf) & $6.85 \pm 3.93$ \\
\hline LAP (kgf) & $7.35 \pm 3.95$ \\
\hline Fear of Falling & Mental Activity & $29.38 \pm 7.61$ \\
Cognition & FES-K (points) & $24.80 \pm 3.71$ \\
Depression & MMSE-K (points) & $14.38 \pm 6.70$ \\
\hline
\end{tabular}

FSI: Foot sensory impairment, TUG: Timed Up and Go test, BBS: Berg Balance Scale, RAD: Muscle strength of right ankle dorsiflexor, LAD: Muscle strength of left ankle dorsiflexor, RAP: Muscle strength of right ankle plantarflexor, LAP: Muscle strength of left ankle plantarflexor, FES-K: Korean Fall Efficacy Scale, MMSE-K: Korean Mini-Mental Status Examination, K-GDS: Korean Foam of Geriatric Depression Scale

$\mathrm{r}=.349$ ). This means that foot sensory impairment in the elderly, on the one hand, is correlated with gait and TUG. On the other hand, it does not generally act as a factor of fear (FES-K), cognition (MMSE-K), or depression (K-GDS) for senior citizens residing at home. It is estimated that the major causes of these results are that this research was targeted at ordinary elderly people who did not complain of discomfort from foot sensory impairment, and subjects' did not have severe foot sensory impairment. Lee et al. [12] categorized those with foot sensation who did not perceive more than four out of 10 sites as having abnormal foot sensory perception. A few people with abnormal foot sensory perception existed in this study.

It has been reported that TUG in the elderly is, on average, 8.1 seconds for those 60 69 years of age, 9.2 seconds for those 70 79, and 11.3 seconds for those 80 99 [20]. Numerous studies have shown that if the TUG score is 13.5 20.1 seconds, risk of falling increases [21,22]. A recent study of 699 senior citizens indicated that a TUG score of 15.96 seconds is a cut-point where recurrent falls can be expected to happen [23]. Based on this study, it is important that further analyzation of factors correlated with TUG should be executed to prevent recurrent falls. Furthermore, the extent to which foot sensations are impaired can be a cause.

TUG was found out to be negatively correlated with BBS. This means that the problem of balance is linked to gait. Bennie et al. [24] reported a similar result. The reason why TUG is used as a dynamic balance scale suggests that TUG is correlated with balance $[25,26]$. This study concludes that TUG does not have any relationship with FES-K, fear of falling, which can be inferred from the fact that FES-K is heavily affected by the experience of falling in subjects [27]. It has been shown that greater experience of falling is associated with higher FES [28]. It can be inferred based upon this result that the subjects in this research did have any experience of falling. Besides, Kwan et al. [29] showed that TUG and FES-K do not 
Table 3. Correlations Between Foot Sensory Impairment, Physical and Mental Activities in Elderly People

\begin{tabular}{|c|c|c|c|c|c|c|c|c|c|c|}
\hline & FSI & TUG & BBS & FES-K & MMSE-K & K-GDS & RAD & LAD & RAP & LAP \\
\hline FSI & 1 & & & & & & & & & \\
\hline TUG & $.349^{*}$ & 1 & & & & & & & & \\
\hline BBS & -.154 & $-.501^{*}$ & 1 & & & & & & & \\
\hline FES-K & -.094 & -.205 & $.380^{*}$ & 1 & & & & & & \\
\hline MMSE-K & -.173 & $-.392^{*}$ & $.473^{* *}$ & .226 & 1 & & & & & \\
\hline K-GDS & .286 & $.479^{* *}$ & -.313 & $-.751^{* * *}$ & $-.433^{* *}$ & 1 & & & & \\
\hline RAD & -.136 & -.322 & .066 & $.331^{*}$ & .154 & -.277 & 1 & & & \\
\hline LAD & -.193 & -.329 & .107 & .287 & .166 & -.231 & $.950^{* *}$ & 1 & & \\
\hline RAP & -.050 & -.304 & .255 & .202 & .211 & -.119 & $.690^{* *}$ & $.631^{* *}$ & 1 & \\
\hline LAP & -.084 & -.235 & .167 & .253 & .196 & -.138 & $.674^{* *}$ & $.664^{* *}$ & $.919^{* *}$ & 1 \\
\hline
\end{tabular}

${ }^{*} \mathrm{p}<.05,{ }^{* *} \mathrm{p}<.01,{ }^{* * *} \mathrm{p}<.001$

FSI: Foot sensory impairment, TUG: Timed Up and Go test, BBS: Berg Balance Scale, MMSE-K: Mini-Mental Status Examination-Korean, FES-K: Korean Fall Efficacy Scale, K-GDS: Korean Foam of Geriatric Depression Scale, MMSE-K: Korean Mini-Mental Status Examination, RAD: Muscle strength of right ankle dorsiflexor, LAD: Muscle strength of left ankle dorsiflexor RAP: Muscle strength of right ankle plantarflexor, LAP: Muscle strength of left ankle plantarflexor

have a causal relationship.

Instead, TUG was found out to be negatively related to MMSE-K (cognition examination) and positively to K-GDS (depression test), which means that a longer TUG test was associated with larger MMSE-K drops and K-GDS increases, based on which physical activities can be interpreted in the that they affect not only cognition but also depression. In a prior study [30], TUG was insignificant when comparing groups according to cognitive function. On the other hand, prior research [31,32] suggested that slower TUG is associated with worse cognitive function. Therefore, opinions on whether or not TUG has a connection with cognitive function vary. However, Ayan et al. insisted that gait speed is affected by cognitive level, and TUG score was directly associated with degree of cognitive severity [31]. In addition, Buckner insisted that medial temporal lobe structures respond to memory and learning, which affects people with cognitive impairment showing alterations in physical activity such as memory, attention, and executive function networks [33].

BBS was significantly interrelated with falls efficacy, as measured by FES-K. Earlier studies also showed that as fear of falling decreases, balance improves [34-36]. As shown in several studies, when performing an exercise program based on balance, falls decreased. Furthermore, gait, balance, and fear of falling worked well [37-40]. Besides, BBS was shown to be positively correlated with MMSE-K (cognition test), and MMSE-K was negatively correlated with K-GDS. Kose et al. suggested that cognitive disorders could become a risk factor of falls. The increase in risk factor of falling was due to cognitive disorders being interconnected with depression and balance impairment according to a prior study [41]. Tinetti et al. and Gostynski et al. also supported this argument by adding that a slight and serious form of cognitive disorders could lead to risk factor of falling $[3,42]$.

It is widely known that fear of falling lessens confidence in normal daily life as well as socially isolates elderly people, accompanied by mobility problems that encourage an inactive lifestyle $[43,44]$. FES-K, a tool that measures fear of falling, was found to be negatively interconnected with K-GDS, which means that as fear of falling increases, 
depression also increases. Several earlier studies indicated that as fear of falling became more serious, symptoms of depression increased [45,46]. In addition, this study confirms that FES-K was interconnected with ankle dorsiflexors of the right foot. Ankle dorsiflexors serve to keep one's balance [47]. It can be inferred that the degree of muscular strength of the ankle dorsiflexors somewhat plays a role in maintaining posture. Furthermore, in support of Whipple et al.'s argument, weakness of the ankle dorsiflexors weakens balance so that fear of falling can increase [48]. There was also a study by Takazawa et al. in which a group of people with ankle dorsiflexor weakness had a risk of falling 5.09 times higher than those with strong ankle dorsiflexors, which supports the correlation mentioned above [49].

\section{Conclusion}

The results of this research confirm that the extent of foot sensory impairment in normal elderly people was correlated with TUG, which showed the most comprehensive correlations to physical and mental activities. As a result, TUG is widely related to the physical and mental activities of general senior citizens. BBS was also shown to be correlated with TUG, FES-K, and MMSE-K. Thus, TUG and BBS might be included in physical and mental check-ups for prevention of falling in elderly people. Further studies on correlations with evaluation criteria for physical and mental activities should lead to the simplification of assessment items.

\section{Acknowledgement}

This research was supported by the Academic Research fund of Hoseo University, Asan, South Korea in 2018 (2018-0126).

\section{References}

[1] Sharp JA, Barber HO. The Vestibulo-ocular Reflex and Vertigo. New York. Raven Press. 1993.

[2] Burt CW, Fingerhut LA. Injury visits to hospital emergency departments: United States, 1992-95. Hyattsville, Maryland. Vital Health Stat 13. 1998.

[3] Tinetti ME, Speechley M, Ginter SF. Risk factors for falls among elderly persons living in the community. N Engl J Med. 1988;319(26):1701-7.

[4] Nevitt MC, Cummings SR, Hudes ES. Risk factors for injurious falls: a prospective study. J Gerontol. 1991; 46(5):M164-70.

[5] Tinetti ME, Doucette J, Claus E, Marottoli R. Risk factors for serious injury during falls by older persons in the community. J Am Geriatr Soc. 1995;43(11):1214-21.

[6] Tinetti ME, Williams CS. The effect of falls and fall injuries on functioning in community-dwelling older persons. J Gerontol A Biol Sci Med Sci. 1998;53(2):M112-9.

[7] Todd C, Skelton D. Health Evidence Network. What are the Main Risk Factors for Falls Among Older People and What are the Most Effective Interventions to Prevent These Falls? Copenhagen. WHO Regional Office for Europe (Health Evidence Network report). 2004.

[8] Segev-Jacubovski O, Herman T, Yogev-Seligmann G, et al. The interplay between gait, falls and cognition: can cognitive therapy reduce fall risk? Expert Rev Neurother. 2011;11(7):1057-75.

[9] Hoogendijk EO, Deeg DJ, Poppelaars J, et al. The Longitudinal Aging Study Amsterdam: cohort update 2016 and major findings. Eur J Epidemiol. 2016;31(9): 927-45.

[10] Dionyssiotis Y. Analyzing the problem of falls among older people. Intern J Gen Med. 2012;5:805-13.

[11] Timar B, Timar R, Gaiță L, et al. The impact of diabetic neuropathy on balance and on the risk of falls in patients with type 2 diabetes mellitus: A cross-sectional study. PLoS One. 2016;11(4):e0154654. 
[12] Lee SY, Kim HH, Choi SH, et al. Clinical usefulness of the two-site Semmes-Weinstein monofilament test for detecting diabetic peripheral neuropathy. J Korean Med Sci. 2003;18:103-7.

[13] Kochman AB, Carnegie DH, Burke TJ. Symptomatic reversal of peripheral neuropathy in patients with diabetes. J Am Podiatr Med Assoc. 2002;92(3):125-30.

[14] Seong DY, Kim JH, Park JW. The effects of changes in foot cutaneous sensation on plantar pressure distribution during gait. J Korean Soc Phys Ther. 2012;24(5):306-12.

[15] Berg K, Wood-Dauphinee S, Williams JI. The balance scale: reliability assessment for elderly residents and patients with an acute stroke. Scand. J. Rehabil. Med. 1995;27(1):27-36.

[16] Embrey DG, Holt SL, Alon G, et al. Functional electrical stimulation to dorsiflexors and plantarflexors during gait to improve walking in adults with chronic hemiplegia. Arch Phys Med Rehabil. 2010;91(5):687-96.

[17] Lee SH, Park WM, Kim SH, et al. The usefulness of clock drawing test as screening for dementia on the basis of the correlation between clock drawing and MMSE-K. J Korea Assoc Family Med. 1997;18(8):785-92.

[18] Chang SM, Lee DW, Kim KW, et al. Measuring cognition in elderly people : Mini-Mental State Examination-Korean Version. Alzheimers \& Dementia: The Journal of Alzheimers association. 2012;8(4):371.

[19] Jung IK, Kwak DI, Cho SH, et al. A Preliminary Study on Standardization of Korean Form of Geriatric Depression Scale(KGDS). J Korean Neuropsychiatr Assoc, 1998; 37(2):340-51.

[20] Guccione AA, Wong RA, Avers D. Geriatric physical therapy, 3rd ed. Elsevier Korea, L.L.C. 2012.

[21] Barry E, Galvin R, Keogh C, et al. Is the Timed Up and Go test a useful pedictor of risk of falls in community dwelling older adults: a systematic review and meta-analysis. BMC Geriatr. 2014;14:14.

[22] Shumway-Cook A, Brauer S, Woollacott M. Predicting the probability for falls in community-dwelling older adults using the Timed Up \& Go test. Phys Ther. 2000; 80(9):896-903.

[23] Kang L, Han P, Wang J, et al. Timed Up and Go Test can predict recurrent falls: a longitudinal study of the community-dwelling elderly in China. Clin Interv Aging. 2017;28(12):2009-16.

[24] Bennie S, Bruner K, Dison A, et al. Measurements of Balance: Comparison of the Timed "Up and Go" Test and Functional Reach Test with the Berg Balance Scale. J. Phys. Ther. Sci. 2003;15(2):93-7.

[25] Wrisley DM, Pavlou M. Physical therapy for balance disorders. Neurol Clin. 2005;23(3):855-74.

[26] Schoene D, Wu SM, Mikolaizak AS, et al. Discriminative ability and predictive validity of the timed up and go test in identifying older people who fall: systematic review and meta-analysis. J Am Geriatr Soc. 2013;61(2):202-8.

[27] Figueiredo D, Neves M. Falls Efficacy Scale-International: Exploring psychometric properties with adult day care users. Arch Gerontol Geriatr. 2018;79:145-50.

[28] Jørstad EC, Hauer K, Becker C, et al. Measuring the psychological outcomes of falling: a systematic review. J Am Geriatr Soc. 2005;53(3):501-10.

[29] Kwan MM, Lin SI, Chen CH, et al. Sensorimotor function, balance abilities and pain influence timed up and go performance in older community-living people. Aging Clin Exp Res. 2011;23(3):196-201.

[30] Eggermont LH, Gavett BE, Volkers KM, et al. Lower-extremity function in cognitively healthy aging, mild cognitive impairment, and Alzheimer's disease. Arch Phys Med Rehabil. 2010;91(4):584-8.

[31] Ayan C, Cancela JM, Gutiérrez A, et al. Influence of the cognitive impairment level on the performance of the Timed "Up \& Go" Test (TUG) in elderly institutionalized people. Arch Gerontol Geriatr. 2013;56(1):44-9.

[32] McGough EL, Kelly VE, Logsdon RG, et al. Associations between physical performance and executive function in older adults with mild cognitive impairment: Gait speed and the timed "Up \& go" test. Phys Ther. 2011;91(8): 
1198-207.

[33] Buckner RL. Memory and executive function in aging and $\mathrm{AD}$ : Multiple factors that cause decline and reserve factors that compensate. Neuron. 2004;44(1):195-208.

[34] Sivakumar R, Radika CM. Analysis of the influence of fear of fall on the score of berg balance scale among the elderly population. Indian Journal of Physiotherapy \& Occupational Therapy. 2012;6(3):267-71.

[35] Ulus Y, Durmus D, Akyol Y, et al. Reliability and validity of the Turkish version of the Falls Efficacy Scale-Internaltional (FES-I) in community-dwelling older persons. Arch Gerontol Geriatr. 2012;54(3):429-33.

[36] Jung MS, Park JW. The relationship between balance test and fear of falling in community dwelling elderly.

J Korean Soc Phys Ther. 2012;24(1):23-8.

[37] Li F, Harmer P, Fisher KJ, et al. Tai chi and fall reductions in older adults: A randomized controlled trial. J Gerontol A Biol Sci Med Sci. 2005;60(2):187-94.

[38] Liu-Ambrose T, Khan KM, Eng JJ, et al. Balance confidence improves with resistance or agility training. Increase is not correlated with objective changes in fall risk and physical abilities. Gerontology. 2004;50(6):373-82.

[39] Lord SR, Castell S, Corcoran J, et al. The effect of group exercise on physical functioning and falls in frail older people living in retirement villages: A randomized, controlled trial. J Am Geriatr Soc. 2003;51(12):1685-92.

[40] Suzuki T, Kim H, Yoshida H, et al. Randomized controlled trial of exercise intervention for the prevention of falls in community-dwelling elderly Japanese women. J Bone Miner Metab. 2004;22(6):602-11.

[41] Kose N, Cuvalci S, Ekici G, et al. The risk factors of fall and their correlation with balance, depression, cognitive impairment and mobility skills in elderly nursing home residents. Saudi Med J. 2005;26(6):978-81.

[42] Gostynski M, Ajdacic-Gross V, Heusser-Gretler R, et al. Dementia, depression and activity of daily living as risk factors for falls in elderly patients. Soz Praventivmed, 2001;46(2):123-30.

[43] Donmez L, Gokkoca Z. Accident profile of older people in Antalya City Center, Turkey. Arch Gerontol Geriatr. 2003;37(2):99-108.

[44] Lajoie Y, Gallagher SP. Predicting falls within the elderly community: comparison of postural sway, reaction time, the Berg balance scale and the Activities-specific Balance Confidence $(\mathrm{ABC})$ scale for comparing fallers and non-fallers. Arch Gerontol Geriatr 2004;38(1):11-26.

[45] van Haastregt JC, Rixt Zijlstra GA, van Rossum E, et al. Feelings of anxiety and symptoms of depression in community-living older persons who avoid activity for fear of falling. Am J Geriatr Psychiatry. 2008;16(3): 186-93.

[46] Gagnon N, Flint AJ, Naglie, et al. Affective correlates of fear of falling in elderly persons. Am J Geriatr Psychiatry. 2005;13(1):7-14.

[47] Runge CF, Shupert CL, Horak FB, et al. Ankle and hip postural strategies defined by joint torques. Gait $\&$ Posture. 1999;10(2):161-70.

[48] Whipple RH, Wolfson LI, Amerman PM. The Relationship of Knee and Ankle Weakness to Falls in Nursing Home Residents: An Isokinetic Study. J Am Geriatr Soc. 1987; 35(1):13-20.

[49] Takazawa K, Arisawa k, Honda S, et al. Lower-extremity muscle forces measured by a hand-held dynamometer and the risk of falls among day-care users in Japan: using multinomial logistic regression analysis. Disabil Rehabil. 2003;25(8):399-404. 